\title{
ESTUDO DA PREVALÊNCIA DA FEBRE REUMÁTICA *
}

Marluce Oliveira Silva **

Vinício Bertolami**

Adolpho A. Cesar Finatti *:

Adih D. Jatene $:$ :

RSPUB $9 / 440$

Silva, M. O. et al. Estudo da prevalência da febre reumática. Rev. Saúde públ., S. Pallo, 13:1-6, 1979.

RESUMO: Foi realizado estudo sobre a prevalència da febre reumática em escolares do primeiro gran de uma unidade escolar do municipio de Sáo Pauto. Brasil. Dos 1.532 allunos da faixa etaria de 7 a 14 anos, foram examinados 316 dos quais surgiram 26 casos ulle exigiram exame cardiológico pormenorizado. O resultado obtido foi o seguinte: 17 normais, 5 portadores de cardiopatias congênitas. 3 suspeitos de atividade reumática e um caso de cardiopatia retumática. Constatou-se a inexistência de qualquer caso de atividade reumática atual, e apenas um caso de cardiopatia reumática, com passado reumático típico. Em relação aos achados brasileiros $\left(1,1 \%, e 0,3 \% \%_{0}\right)$, o presente resultado não difere estatisticamente $(P>0,20 \%)$. Comenton-se o custo da investigaçáo que resultou na descoberta de apenas um caso de doença reumática, já com comprometimento orovalvar, e a posiçào que a saúde pública ocupa em relação aos demais prohlemas observados, tais como: verminose, cárie dentária, subnutrição e outros.

Uniteruns: Febre reumática, prevalência. Escolares, S. Paulo, SP, Brasil.

\section{I $N$ T RODUCA $\mathrm{O}$}

"Em vários paises desenvolvidos, a incidência da febre reumática tem diminuído consideravelmente durante os últimos decênios. Como conseqüência, existe a tendência de se menosprezar a importância sanitária da febre reumática, na suposição de que a enfermidade pode diminuir ou desaparecer espontaneamente ao melhorar o nível de vida. Sem dúvida, porém, mes- mo nessas sociedades de nivel elevado, continua havendo ilhas de pobreza, onde persiste uma incidência relativamente alta de febre reumática e de outras enfermidades endêmicas, o que converte a "erradiação da febre reunática" em uma esperança inatingida" 3 .

Muitas populações estão longe de alcançar o nivel sócio-econômico com o qual se

* Trabalho apresentado no XIX Congresso Brasileiro de Higiene / 1 \% Congresso Paulista de Saúde Pública - 10 a 14 de Outubro/77 - Anhembi, São Paulo.

* Do Instituto "Dante Pazzanese" de Cardiologia da Coordenadoria de Assistencia Hospitalar - Secretaria de Estadio da Saire. Av. Dr. Dante Pazzanese. 50 - monon - São Paulo. SP - Brasil 
SILVA, M. O, et al. Estudo da prevalência da febre reumática. Rer, saúde públ., S. Paulo. $13: 1-6, \quad 1979$

pode esperar a diminuição da febre reulmática, através do melhoramento das condiçōes de vida. Na febre reumática, como em qualquer outra enfermidade, temse que atacar em ambas as direções 0 circulo pobreza-enfermidade-pobreza. Subsiste, indubitavelmente, a questāo das prioridades, já que em qualquer sociedade existem muitos outros problemas sanitários que disputam os limitados recursos disponiveis.

Conforme opiniāo de vários comitês de peritos da Organização Munclial de Saúde", pode-se prevenir a febre e a cardiopatia reumáticas com o tratamento adequado das infecções estreptocócicas. A prevenção das recaídas é relativamente fácil e barata; seu custo é provavelmente muito menor do que, por exemplo, o tratamento cirúrgico de um paciente com estenose mitral ou insuficiência aórtica. Os pacientes com cardiopatia reumática podem viver como inválidos durante vários decênios e a sociedade não deve ignorar as conseqüências pessoais ou econômicas deste fato.

Segundo a orientação da Organização Mundial de Saúde, a luta comunitária contra a febre reumática deve constituir-se através do estabelecimento de programas experimentais em diversos paises e meios, que, se resultam eficazes, servirão como modelo. Baseando-se nessa orientação é que O Instituto "Dante Pazzanese" de Cardiologia da Coordenadoria de Assistência Hospitalar da Secretaria de Saúde do Estado de São Paulo, elaborou e executou estudo de prevalência da febre reumática, com a finalidade de fornecer subsidios para:

- planejamento de futuros programas a serem executados em unidades escolares;

- possibilitar estimativa das proporções da doença reumática na população escolar;

- poder estimar as possibilidades de se traçar normas profiláticas, após a avaliação dos resultados.

Pretendeu-se dar a este estudo características de programação de Saúde Pública; para isso utilizou-se uma equipe multiprofissional na orientação do professor para a sua participação efetiva no programa.

\section{METODOLOGIA}

Escolheu-se para o desenvolvimento do presente estudo uma Unidade Escolar de primeiro grau que oferecesse condiçōes adequadas, tais como:

a) Tipo de população: faixa etária de 7 a 14 anos, idade mais frequiente das manifestações iniciais da doença; condições sócio-econômicas (famílias operárias, baixo poder aquisitivo, condições de vida precárias); residente em bairro da periferia.

b) Localização da escola: de fácil acesso à equipe de saúde e laboratório de análise situado em local accessivel aos alunos.

c) Receptividade por parte da diretoria e do corpo docente da escola.

A unidade escolar "Valentim Gentil" preencheu perfeitamente os requisitos previamente estabelecidos. Seus alunos do turno diurno, num total de 1.532 , estavam na faixa etária de 7 a 14 anos e constituíram objeto do presente estudo.

Para a consecução das finalidades do presente estudo, o professor foi considerado elemento de real importância na descoberta de casos e no controle da doença. Partiu-se do principio que estando ele em contato diário e direto com a criança teria condições de, observando os alunos, identificar aqueles que apresentassem sintomas ou sinais característicos da doença reumática, e de imediato encaminhá-los ao médico, como também seria ótimo elemento para colaborar durante a convalescença e reabilitação da criança afetada pela doença.

Para dar condições ao professor desempenhar o seu papel, conforme era esperado, uma equipe multiprofissional do Instituto "Dante Pazzanese" de Cardiologia (médicos, enfermeiras e educador de saúde pública, assistente social e conselheira de reabilitação) ministrou curso com noções sobre: epidemiologia, transmissão, profilaxia e tratamento da febre reumática, orientação educacional e vocacional, reabi- 
SILVA, M. O. et al. Estudo da prevalência a a febre reumática. Rev. Saúde públ., S. Paulo, $13: 1-6,1979$

litação, convalescença e os aspectos emocionais da criança afetada pela doença.

Foram elaborados formulários de "Estudo das possibilidades de antecedentes reumáticos". A criança que fosse identificada como apresentando sinais ou sintomas característicos da febre reumática, teria a sua mãe, ou responsável, convocada para responder às perguntas nele contidas, através de entrevista com a professora. Paralelamente, em reuniões, os pais deveriam ser orientados no sentido de estarem alertas a quaisquer manifestações da doença em seus filhos e levarem ao conhecimento da escola os problemas de saúde que, no passado da criança, tenham tido semelhança sintomatológica com a doença reumática.

Preenchidos os formulários, a criança era encaminhada, em companhia da mãe, a exame médico na própria escola. Aquelas que apresentavam qualquer anormalidade à ausculta cardíaca e/ou uma história de passado reumático típico eram encaminhadas ao Instituto "Dante Pazzanese" de Cardiologia para complementação dos exames e elucidação do diagnóstico cardiológico. As que apresentavam qualquer outro problema não especifico de cardiologia eram encaminhadas aos Centros de Saúde, a outros especialistas e/ou a exames laboratoriais. Solicitava-se que fossem trazidos os resultados de exames laboratoriais e/ou relatório médico, para prescrição terapêutica e conclusão diagnóstica de todos os casos atendidos. Objetivava-se com essa medida conseguir resultados mais gerais dos problemas de saúde dos escolares para uma estatística da incidência desses problemas.

\section{AVALIACÁO PARCIAL DO PROJETO DURANTE A EXECUÇAO MODIFICAÇÃO DA METODOLOGIA}

Após dois meses de execução do trabalho com a escola, reuniu-se a equipe de saúde com os professores para uma avaliação. Com base na análise dos formulários, dos encaminhamentos para exame médico e na observação da atuação dos professores, foram identificados os seguintes problemas: a) Divergência entre conteúdo dos formulários preenchidos pelos professores e anamnese clínica. Identificou-se como causa desse problema, o fato de ser a entrevista para obtenção das informações realizada, muitas vezes, com o próprio aluno, gerando do desconhecimento a incoerência das respostas. b) A triagem para exame médico feita pelos professores, não correspondia ao conteúdo ministrado no curso c) Falta de entrosamento dos professores no sentido de procurar o médico para conhecimento dos resultados dos exames clínicos do aluno por eles encaminhado. d) $O$ não encaminhamento aos médicos dos resultados dos exames laboratoriais e relatório médico de outros especialistas, dificultando, assim, uma conclusão diagnóstica. e) O encaminhamento da criança pelos professores para exame médico, muitas vezes, sem a presença da mãe ou pessoa responsável dificultando a obtenção de informações para a anamnese clínica.

Em função dos problemas levantados, deram-se novamente orientações sobre os critérios que deveriam ser utilizados para triagem dos alunos a serem examinados, sobre os procedimentos para o preenchimento do formulário de estudo das possibilidades de antecedentes reumáticos, e finalmente como o professor deveria proceder para envolvimento da familia do aluno no estudo, sem o que não se poderia fazer nenhum trabalho educativo.

Nas visitas de supervisão, que sucederam à reunião mencionada, observou-se que 0 número de crianças selecionadas para 0 exame médico decrescia sensivelmente a cada semana. Foi realizado um levantamento das fichas clínicas dos alunos até então examinados, tendo-se chegado à conclusão de que o número de atendimentos não estava sendo representativo e satisfatório, se considerássemos: a capacidade de atendimento de cada profissional; o tempo decorrido desde o início do trabalho; o número total de crianças que representa nossa amostra (1532). 
SILVA, M. O. et al. Estudo da prevalência da febre reumática. Rev. Saúde públ., S, Paulo, $13: 1-6, \quad 1979$

Em virtude disso, decidiu-se mudar a dinâmica da triagem que havia sido planejada para ser feita exclusivamente em função da identificação, pelos professores, de sinais e sintomas associados ou característicos da febre reumática nas crianças. Assim, a professora ou a diretora encaminharia aos médicos aquelas crianças que respondessem afirmativamente à perguntas como estas: Sente freqüentemente dores de garganta, de ouvido, nas juntas? Sente falta de ar, cansaço? Costuma perder sangue pelo nariz? $E$, através de breve exame, o médico selecionaria:

1. crianças com sopro

2. crianças com arritmias

3. crianças com taquicardia exagerada

4. crianças com sinais visíveis de reumatismo

5. crianças com história de passado reumático.

Como todo programa envolve um processo dinâmico e flexível, pretendeu-se, com essa modificação, a aplicação de medidas que melhor demonstrassem a eficácia do estudo e favorecessem melhores resultados.

\section{RESULTADOS}

Dentre os 1.532 escolares, o corpo docente da unidade escolar, seguindo os critérios estabelecidos, encaminhou para exame médico 316 escolares, ou seja, 20,6\% do total. Desse número surgiram 26 casos que exigiram exame cardiológico pormenorizado com eletrocardiograma, Raio $X$ de tórax, exames laboratoriais, além do exame clínico cardiológico. Foram obtidos os seguintes resultados dos casos encaminhados ao Instituto "Dante Pazzanese" de Cardiologia :

a) Dezessete escolares foram considerados normais, apresentando exclusivamente sopros funcionais; em nenhum se confirmou história de febre reumática e outras cardiopatias. b) Cinco eram portadores de cardiopatias congênitas ( 4 com estenoses aórticas e um com tetralogia de Fallot), esse último encaminhado à cirurgia para correção total.

c) Três crianças declararam durante a avaliação anamnéstica terem sido acometidas de sintomas articulares sugestivos de febre reumática; nenhuma delas apresentava alterações no exame físico do ponto de vista cardiovascular, e os exames laboratoriais de prova de atividade reumática resultaram normais; um desses 3 casos apresentava história de recorrência de sintomas e vinha há cerca de 2 anos fazendo uso de Benzetacil, profiláticamente. As provas de atividade reumática resultaram negativas e a orientação foi continuar com uso de Benzetacil. Aos outros dois casos, preferiu-se não fazer esquema profilático pelo fato de não ter havido recorrência de sintomas, nem evidência de comprometimento infeccioso estreptocócico, após o primeiro e único episódio articular, referido na anamnese.

Saliente-se que, nesse grupo de três crianças, os dados anamnésticos fornecidos apenas sugeriram atividade reumática no passado.

d) Um apresentava história de atividade reumática típica no passado e, ao exame físico, foi evidenciada presença de lesão orovalvar, compatível com diagnóstico de insuficiência mitral; esse paciente encontrava-se fazendo uso profilático de Benzetacil e sob orientação e vigilância do Instituto "Dante Pazzanese" de Cardiologia. Atualmente tem capacidade funcional grau II e faz reavaliações temporárias.

Paralelamente ao estudo para apurar a prevalência da doença reumática do coração em escolares de 7 a 14 anos, na unidade escolar "Valentim Gentil", houve uma preocupação por parte da equipe em desenvolver um trabalho mais geral com características de programação de Saúde Pública. A criança era examinada não apenas sob o ponto de vista cardiaco, mas 
SILVA, M. O. et al. Estudo da prevalência da febre reumática. Rev. Saúde públ., S. Paulo, $13: 1-6,1979$

como um todo, para prevenção e tratamento de outras moléstias.

Infelizmente, porém, não se teve condições de se obter dados consistentes, porquanto muitos dos resultados não chegaram ao conhecimento dos autores.

Pode-se, adiantar, no entanto, que nos 316 alunos examinados os problemas mais frequientes foram:

Verminose : 190 casos (com exame de fezes);

Cárie dentária : 132 casos

Sub-nutrição : 35 casos

Escabiose : 34 casos

Problemas oftalmológicos : 29 casos

Problemas ortopédicos : 4 casos

Outros problemas foram encontrados, porém, em número menos representativo, como sejam: ginecológicos, neurológicos e tisiológicos.

\section{COMENTARIOS E CONCLUSÕES}

No presente estudo foi constatada a inexistência de qualquer caso de atividade reumática atual. Encontrou-se, no entanto, um caso $\left(0,7^{\circ} \%\right.$ oo $)$ de cardiopatia reumática com passado reumático típico, segundo os critérios clássicos de Jones. Encontraram-se outros tipos de passado reumático sem cardiopatias, entretanto, o número foi maior de cardiopatias congênitas: 4 casos de estenose aórtica em evolução e um de tetralogia de Fallot.

Embora este estudo tenha tido características diferentes das pesquisas epidemiológicas realizadas por Silva e col. ${ }^{2}$ e Laganá e col. ${ }^{1}$, os nossos achados confirmam aproximadamente os resultados das pesquisas citadas. Realmente, enquanto que na pesquisa epidemiológica nas escolas municipais de São Paulo, Silva e col.2 encontraram 5 casos de cardiopatia reumática em 4.376 escolares pesquisados $(1,1 \%)$ e Laganá e col. ${ }^{1}$ encontraram nas escolas de Santo André um caso em $3.285\left(0,3^{\circ} \%\right.$, neste estu- do encontrou-se um caso em 1.532 escolares pesquisados.

Podemos afirmar que os nossos achados não diferem estatisticamente dos resultados de Silva e col. ${ }^{2}$ e de Laganá e col. ${ }^{1}\left(\chi^{2}=\right.$ $1,84 ; \mathrm{G} 1=2 ; \mathrm{P}>0,20)$.

Persiste pois, ainda, a interrogação quanto à posição que ocupa a febre reumática entre os problemas de Saúde Pública, quando a alta incidência continua sendo de verminose, subnutrição, cárie dentária, escabiose e deficiência visual.

Em conseqüência dos resultados encontrados, chega-se à conclusão de que não se justifica a elaboração de um plano nos mesmos moldes, para ser desenvolvido em outras unidades escolares, principalmente se avaliarmos os custos de um programa semelhante. Poder-se-á sugerir, no entanto, a longo prazo, a inclusão de noções de febre reumática, no programa geral de preparo do professor, para que esses estejan alertas às primeiras manifestações da doença ou às infecções em geral, nos escolares, e à necessidade de encaminhá-los para exame médico.

Segundo as recomendações da Organização Mundial de Saúde ${ }^{3}$ tem-se levado a efeito projetos e estudos experimentais em diversas partes do mundo, e esses têm demonstrado que se pode obter boa cobertura e resposta satisfatória dos pacientes. Esses programas consistem em submeter, cada ano, os grupos mais expostos, principalmente as crianças em idade escolar, a exames bacteriológicos e clínicos.

No caso de São Paulo, em particular, entende-se que, para a implantação sistemática desse programa, ter-se-ia que estabelecer boas relações de trabalho entre os órgãos de Educação e Saúde, através de um trabalho em equipe multiprofissional, havendo uniformidade de pensamento, disponibilidade de recursos materiais e uma participação realmente efetiva dos professores de 10 grau de ensino. 
SILVA, M. O. et al. Estudo da prevalência da febre reumática. Rer. Saúde públ., S. Paulo, $13: 1-6, \quad 1979$

\section{AGRADECIMENTOS}

Agradecemos aos Drs. Antonio Carlos S. Nery, Alair Rocha de Castro e Iracy Almeida Bojadsen, pela participação no Trabalho como médicos do Instituto "Dante Pazzanese" de Cardiologia. Às enfermeiras de Saúde Pública, Terezinha Rute V. Bose e Maria Tamitaro Kako; à Rodrigo
A. C. Farias e Maria Angela Marzulli do Instituto "Dante Pazzanese" de Cardiologia pela colaboração. Às Professoras e Diretora da Unidade Escolar "Valentim Gentil" o nusso mais profundo reconhecimento pelo valioso apoio e participação, sem o que não teria sido possivel a realização do presente estudo.

Silva, M. O. et al. [A study of prevalence of rhellmatic fever] Rev. Saúde públ., S. Pallo, 13:1-6, 1979 .

ABSTRACT: A medical and public health group of the city of Säo Paulo's Dante Pazzanese Institute of Cardiology (Brazil) chose the Valentim Gentil School's 1532 students to be checked for signs of rheumatic fever. Of these 1532 students, 316 were examined; their ages ranged from 7 to $14 . \quad$ Twenty-six required detailed cardiologic examination, which gave the following results: seventeen were normal; five had congenital heart disease; three showed signs of rheumatic activity, not confirmed; and there was one case of rheumatic cardiopathy. No cases of confirmed rheumatic activity were found during the examinations and only one rheumatic cardiopathy with typical rheumatic fever. Other Brazilian statistics for this t!pe of stud $y^{\prime}$ are $1.1 \%$ and $0.3 \%$. Therefore, $P>0.20 \%$ is, statistically, not significant. From the standpoint of public health, the findings were out of proportion to the costs of the study when so muth needs to be done for those needing care for verminosis, dental problems, malnutrition and so one.

UnITERus: Rhelmatic fever, prevalence. School children, S. Paulo, Brazil.

\section{REFERENCIAS BIBLIOGRÁFICAS}

1. LAGANá, R. et al. Prevalência de cardiopatia congênita e da doença reumática do coração entre escolares do Município de Santo André. Arq. bras. Cardiol., 23:415-9, 1970.

2. SILVA. W. $N$. da et al. Epidemiologia da doença reumática do coração. Arq. bras. Cardiol., $22: 235-341.1969$.
3. STRASSER. T \& ROTTA, Y. J. La lucha contra la fiebre reumática y la cardiopatia reumática, una reseña de las actividades de la OMS. Cron. OMS, 2 : :53-9, 1973 .

Recebido nara publicaşäo em 04/05:1978 Aprovado para publicaçäo em 09/08:1978 